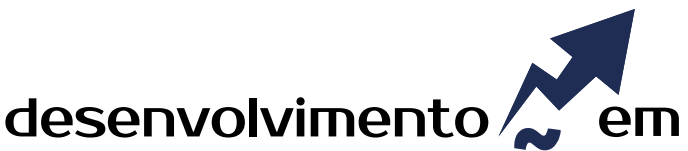 QUESTÃO
}

\section{A Relação Universidade-Empresas Traz Prejuízo ao Desempenho Acadêmico de uma Universidade Pública?}

http://dx.doi.org/10.21527/2237-6453.2020.52.267-285

Recebido em: 18/11/2019

Aceito em: 4/3/2020

Camila Aparecida Fonseca Souza , ${ }^{1}$ David Ferreira Lopes Santos ${ }^{2}$

\begin{abstract}
RESUMO
Esta pesquisa explorou a relação Universidade-Empresas a partir de um estudo de caso da Faculdade de Ciências Agrárias e Veterinárias (FCAV), da Universidade Estadual Paulista (Unesp), visando a entender quais os efeitos dessa aproximação no desempenho acadêmico dos docentes de uma universidade pública. Para tanto, avaliou-se comparativamente a performance de docentes com parcerias junto a instituições de mercado e aqueles que não o fazem, por meio da Fundação de Apoio à Pesquisa, Ensino e Extensão (Funep). As unidades de análise foram os docentes vinculados aos 11 Programas de Pós-Graduação da FCAV, com escopo temporal de 5 anos (2011 a 2016). As variáveis foram construídas a partir da fundamentação teórica do estudo. Os dados foram tratados mediante análise discriminante. Os 169 docentes que possuem projetos junto ao mercado constituem o Grupo 1. Os 127 que não apresentaram projetos estão no Grupo 0 . Os resultados sinalizam que o envolvimento dos docentes em projetos com empresas para geração de tecnologia não concorre com os outros objetivos da FCAV. Verificou-se que em nenhuma das variáveis estudadas a produção dos docentes com recursos junto ao mercado é inferior aos que não possuem, ao contrário, para algumas variáveis, os resultados foram superiores. Constatou-se que os docentes com projetos adjuntos à Funep são os que mais captam recursos financeiros. Concluiu-se que docentes com projetos na Funep quando não mostram o mesmo desempenho daqueles que não o fazem, apresentam resultados superiores, confirmando que a relação Universidade-Empresas não compromete a produtividade acadêmica desses profissionais.
\end{abstract}

Palavras-chave: Agronegócio. Ciência, tecnologia e inovação. Ecossistema. Hélice tríplice.

\section{DOES UNIVERSITY-FIRM RELATIONSHIP BRING LOSS FOR THE ACADEMIC PERFORMANCE OF A PUBLIC UNIVERSITY?}

\section{ABSTRACT}

This research explored the University-Business relationship based on a case study of the Faculdade de Ciências Agrárias e Veterinárias (FCAV), Universidade Estadual Paulista (Unesp), aiming understand the effects of this approximation on the academic performance of public university. To do so, was evaluated the performance of teachers with partnerships with market institutions and those who do not, through the Fundação de Apoio a Pesquisa, Ensino e Extensão (Funep). The analysis unit was the teachers linked to the 11 Postgraduate Programs of the FCAV, with a 5-year time span (2011 to 2016). The variables were constructed based on the theoretical basis of the study. The data were treated by discriminant analysis. The 169 teachers who have projects with the market constitute Group 1, so the 127 that did not present projects are in Group 0 . The results indicate that the involvement of teachers in projects with companies for technology generation do not compete with the other objectives of the FCAV. It was verified that in none of the studied variables the production of the teachers with resources to the market is inferior to those that do not have, in contrast, for some variables, the results were superior. It was found that the teachers with projects attached to Funep are the ones that attract the most funds. It was concluded that teachers with projects with Funep when they do not mirror the same performance of those who do not, present superior results, confirming that the University-Business relation does not compromise the academic productivity of these professionals.

Keywords: Agribusiness. Science, technology and innovation. Ecosystem. Triple helix.

\footnotetext{
${ }^{1}$ Graduada em Administração pela Universidade Estadual Paulista Júlio de Mesquita Filho (Unesp). http://lattes.cnpq.br/2709137629514057. https://orcid.org/0000-0003-4486-3927. camilafsouza93@gmail.com

${ }^{2}$ Doutor em Administração de Empresas pela Universidade Presbiteriana Mackenzie (Mackenzie). Professor da Universidade Estadual Paulista Júlio de Mesquita Filho (Unesp). http://lattes.cnpq.br/5017639694729451. https://orcid.org/0000-0003-3890-6417. david.lopes@fcav.unesp.br
} 
A infraestrutura de Ciência e Tecnologia brasileira é complexa e envolve um elevado número de instituições, incluindo universidades públicas, privadas, centros de pesquisa tecnológica e faculdades, além de abarcar a interação entre os agentes, com vistas ao desenvolvimento tecnológico e científico, com desdobramentos em inovações (LEMOS; CARIO, 2017; COSTA et al., 2017).

Em 2016, o dispêndio nacional em ciência e tecnologia (C\&T) em relação ao Produto Interno Bruto (PIB) foi de 1,53\%; para o mesmo período, o dispêndio nacional em ciência e tecnologia (C\&T) e os investimentos em pesquisa e desenvolvimento (P\&D) foram de 95,6 e 79,2 bilhões, respectivamente (MCTIC, 2018). Outro dado importante acerca dos indicadores nacionais de Ciência, Tecnologia e Inovação (CT\&l) diz respeito ao valor da renúncia fiscal do governo federal segundo as leis de incentivo à pesquisa, desenvolvimento e capacitação tecnológica, que no ano de 2018 foi de $R \$$ 8,6 bilhões em valores correntes (MCTIC, 2018).

As universidades brasileiras, especialmente as públicas, têm funcionado como uma "antena" que capta, codifica e transmite o conhecimento gerado nos países centrais, de modo a aplicá-lo na realidade brasileira, tendo em vista que Ciência, Tecnologia e Inovação constituem fontes diferenciadoras no que tange ao desenvolvimento social e econômico de países e regiões (BASTOS; BRITTO, 2017).

Diante desse cenário, o compromisso das universidades com a sociedade está fundamentado em três pilares básicos: o ensino, a pesquisa e a extensão; ao passo que o setor empresarial tem seus objetivos direcionados a atender demandas de um mercado consumidor cada vez mais exigente e, para tanto, tem intensificado os esforços em investimentos voltados à pesquisa e desenvolvimento tecnológico (BERNI et al., 2015). Assim, na medida em que se expandem as necessidades da sociedade moderna, desponta a conveniência de interação entre universidades e empresas para alcançar objetivos comuns (BERNI et al., 2015).

Nessa linha, as universidades são fontes imprescindíveis para a proposição de novos projetos de pesquisa no Brasil, uma vez que ofertam tanto o conhecimento mais geral por meio de recém-graduados quanto o saber mais específico retido por pesquisadores com notório destaque internacional, além de possuir caráter vital na formação de recursos humanos e disseminação de novas tecnologias, transformando a aprendizagem adquirida em âmbito individual em competências ou capacidades tecnológicas, que doravante serão usufruídas pelas empresas e demais entidades (DEWES; DALMARCO; PADULA, 2015).

Tendo em vista o papel crucial da inovação para o desenvolvimento tecnológico e econômico dos países, o tema gestão de tecnologias tem apresentado crescente destaque, especialmente no tocante àquelas geradas em instituições que promovem P\&D e cooperam com as práticas de CT\&I, como as universidades e os institutos de pesquisa (GARNICA; TORKOMIAN, 2009; OLIVEIRA, 2016).

Dentro dessa visão, a utilização do conhecimento originado nas universidades representa rica fonte de informação e capacitação para o desenvolvimento de inovações, ainda que a transferência de tecnologias entre universidade e setor produtivo se revele 
um caminho longo e repleto de entraves, por conta dos desafios encontrados no interior dessas instituições no que diz respeito ao estabelecimento de regulamentações acerca da gestão tecnológica e regras para comercialização (GARNICA; TORKOMIAN, 2009).

Em virtude das novas tendências e dos desafios que as universidades brasileiras têm enfrentado, faz-se necessário, por parte das Instituições de Ensino Superior (IESs), rever suas políticas de parcerias e definir novos enfoques, mediante estudos de casos que retratem esse cenário e incitem mudanças (GARNICA; TORKOMIAN, 2009).

Em 2017, 35.380 cursos de Graduação foram ofertados no Brasil em 2.448 IESs para um total de 8.286 .663 estudantes matriculados, observando-se que 296 das IESs são públicas; das quais $41,9 \%$ são estaduais, $36,8 \%$ são federais e $21,3 \%$ são municipais, representando respectivamente 124, 109 e 63 instituições de ensino (INEP, 2017).

A despeito da importância do tema e do papel essencial que as universidades desempenham no desenvolvimento tecnológico e econômico (BERBEGAL-MIRABENT; RIBEIRO-SORIANO; GARCÍA, 2015; DABIC; GONZÁLEZ-LOUREIRO; DAIM, 2015; CALCAGNINI; FAVARETTO, 2015), estudos empíricos e importantes ensaios teóricos têm questionado o tratamento secundário que as universidades brasileiras conferem ao tema, cuja perspectiva ainda é direcionada para o modelo linear clássico do progresso científico (DOSSA; SEGATTO, 2010; IACONO; ALMEIDA; NAGANO, 2011; BASTOS; BRITTO, 2017; LEMOS; CARIO, 2017).

Notadamente diferentes trabalhos discorrem acerca dessa temática, cabendo enfatizar que Quandt, Bezerra e Ferraresi (2015) investigaram a atuação da universidade brasileira como provedora de tecnologias, Dewes, Dalmarco e Padula (2015) abordaram o papel da universidade para o desenvolvimento dos Sistemas Nacionais de Inovação, Garnica e Torkomian (2009) explanaram quanto ao patenteamento e à comercialização de tecnologias nas universidades públicas e Chiarini e Vieira (2012) pleitearam ante a carência de pesquisas no sentido de propor medidas que desencadeiem a integração entre as instituições educacionais de ensino superior e os esforços brasileiros em CT\&। no âmbito empresarial.

A literatura, contudo, aponta alguns entraves na relação Universidade-Empresas no que diz respeito a aspectos burocráticos, legais e culturais; dificuldades no acesso, gestão e controle dos mecanismos de informação e na transferência dos resultados incipientes ao mercado, além da complexidade em conciliar questões político-ideológicas relacionadas à posse da propriedade intelectual e ao domínio do conhecimento (SANTANA; PORTO, 2009; CLOSS et al., 2012; DIAS; PORTO, 2013; BERNI et al., 2015; MACHADO; SARTORI, 2018).

Como o desempenho acadêmico de uma universidade perpassa diretamente pelo trabalho dos seus docentes que, em última instância são os vértices que convergem às ações em ensino, pesquisa e extensão, há a necessidade de direcionar o foco de análise para os docentes, que são aqueles também que prospectam e geram as ações de interação entre a universidade e as empresas (QUANDT; BEZERRA; FERRARESI, 2015).

Desse modo, a questão que motivou a realização desse estudo foi: A relação Universidade-Empresas traz prejuízo ao desempenho acadêmico de uma universidade pública? 
A originalidade dessa pesquisa pode ser definida pelo seu escopo e aplicação. A avaliação do ambiente de inovação baseado na relação Universidade-Empresas pode contribuir para o desenvolvimento de uma Instituição de Ensino Superior, especificadamente um estudo de caso analisando a Faculdade de Ciências Agrárias e Veterinárias de Jaboticabal (FCAV), da Universidade Estadual Paulista "Júlio de Mesquita Filho" (Unesp).

$\mathrm{O}$ caso da FCAV/Unesp é relevante, pois esta é uma das principais escolas de formação de recursos humanos, nos níveis de Graduação e Pós-Graduação, e tecnologia em uma das atividades econômicas mais competitivas do Brasil, o agronegócio. A FCAV possui 11 programas de Pós-Graduação stricto sensu, e já formou mais 1.900 doutores e 2.400 mestres. Atualmente, $10 \%$ da produção científica nacional, qualificada na Web of Science em Ciências Agrárias, tem a participação de docentes da FCAV (UNESP, 2019).

Ademais, a FCAV conta com a Fundação de Apoio à Pesquisa, Ensino e Extensão (Funep), que tem como missão promover o conhecimento científico, tecnológico, cultural e social na comunidade universitária por meio de parcerias público-privadas, satisfazendo os objetivos comuns (FUNEP, 2019). Possui mais de 40 anos de existência e administra, anualmente, mais de 200 contratos de projetos com docentes da Unesp e instituições externas (FUNEP, 2019).

Diante dessas informações, entende-se que seria pertinente, como propósito de estudo, o seguinte objetivo: avaliar os efeitos da relação Universidade-Empresas no desempenho acadêmico dos docentes da FCAV. Para tanto, avalia-se comparativamente o desempenho de docentes com parcerias junto as instituições de mercado e aqueles que não apresentam tais cooperações, como forma de responder à pergunta que motivou essa pesquisa.

Para alcançar o objetivo proposto este documento foi estruturado em mais quatro seções subsequentes. Na segunda, apresenta-se a fundamentação teórica do estudo que permitiu análise empírica da pesquisa realizada. A seção posterior discorre sobre os materiais e métodos que balizaram a pesquisa e delimitaram a extensão e aplicação dos resultados. A quarta seção apresenta os resultados da pesquisa e sugere uma discussão com a literatura abordada. Por último expõem-se as considerações finais e implicações deste trabalho. As referências finalizam o estudo.

\section{FUNDAMENTAÇÃO TEÓRICA}

Nesta seção são apresentadas as formulações teóricas que contribuíram para o desenvolvimento da pesquisa acerca do conceito de Ambiente de Ciência, Tecnologia e Inovação, com ênfase na relação Universidade-Empresas. Na sequência são elucidados os principais argumentos relativos ao ambiente de inovação voltado ao agronegócio brasileiro, tendo em vista o contexto agrícola em que a FCAV está inserida.

\section{Gestão da Inovação na Relação Universidade-Empresas}

As profundas alterações da sociedade capitalista dependem de interações do ambiente institucional em que diferentes agentes estão inseridos com vistas ao desenvolvimento científico e tecnológico com desdobramentos em inovações organizacionais, produtos e/ou processos (LEMOS; CARIO, 2017; COSTA et al., 2017). 
Inovar é produzir, assimilar, adotar ou explorar uma novidade, que resulta no estabelecimento de produtos, processos, estratégias de marketing ou métodos organizacionais novos ou significativamente melhorados (CROSSAN; APAYDIN, 2010). De forma ampla, portanto, inovação é um meio de criar, transformar, corrigir e adaptar ideias de modo a promover rupturas paradigmáticas que atuem como vetor de desenvolvimento humano (OECD, 2018).

O apoio institucional à inovação no Brasil vem se tornando um mecanismo estruturado e coordenado, provendo o aumento da perspectiva de inovação para o país, haja vista que as instituições brasileiras trabalham para o fomento à ciencia e tecnologia tanto em termos de publicações e visibilidade como mediante atribuição de subsídios para estudantes de Pós-Graduação e financiamento de pesquisas, ambicionando reflexos futuros positivos em inovação e desempenho empresarial, no entanto ainda é necessário superar limitações e atender às demanda sociais comuns aos países em desenvolvimento (FRANKA et al., 2016; SANTOS; BASSO; KIMURA, 2018).

Assim, apesar dos vários esforços institucionais e regulatórios criados pelo Brasil ao longo do tempo para promover o desenvolvimento tecnológico, é imprescindível extinguir a lacuna entre o conhecimento gerado no país e a fronteira tecnológica de produção existente nos mercados mais avançados (SANTOS; BASSO; KIMURA, 2018).

A forma e intensidade com que as diferentes instituições e agentes interagem dentro de um ambiente de inovação também alteram a cooperação entre os grupos, a cultura empreendedora do local, a visão estratégica e econômica, construindo uma rede complexa que se estrutura em torno de um objetivo comum, associado ao conhecimento, aprendizagem, tecnologia, ciência, demanda e política, resultando em vantagens para todos os intervenientes (COSTA et al., 2017; KIEFT; HARMSEN; HEKKERT, 2017).

Para Maciel (2001), a concepção de ambiente de inovação abarca o conjunto de condições, obstáculos, possibilidades e estímulos para a inovação em uma determinada estrutura social. Ambiente de inovação refere-se, portanto, aos aspectos políticos, econômicos, sociais e culturais que incitam ou inibem a inovação em um determinado espaço geográfico (CARVALHO; MACHADO, 2013).

O ambiente de inovação é onde se desenvolve a infraestrutura tangível e intangível preponderante para o surgimento da inovação, haja vista que combina o meio interno, que é o alicerce do processo, no que concerne à compreensão dos métodos necessários ao desenvolvimento da inovação, incumbido de criar e coordenar novas ideias, com o ambiente externo, que por sua vez engaja-se nas transações inerentes aos sistemas de inovação, na medida em que são abrangentes e incorporam condições existentes no mercado e influenciam as mudanças organizacionais, mediante a união de grupos criados para obter e alocar recursos, que juntos resultaram no longo prazo em inovação (MACHADO; BARZOTTO, 2012; CARVALHO; MACHADO, 2013).

Freeman (1995) foi o precursor no uso da expressão "Sistema Nacional de Inovação". Em seus trabalhos o autor procurou discutir o potencial das diferentes nações em explorar o processo de inovação e difusão de tecnologia em benefício próprio (LEMOS; CARIO, 2017). Logo, é plausível inferir que os ambientes de inovação são espaços destinados à pesquisa e à difusão da tecnologia e nesse sentido o foco em conhecimento e 
interatividade sustenta a ideia dos sistemas de inovação, que têm em seu escopo contribuir para o desenvolvimento da capacidade de inovar e aprender (CARVALHO; MACHADO, 2013; LEMOS; CARIO, 2017).

Nessa conjuntura, a inovação de forma genérica é o meio pelo qual as empresas colocam em prática os novos produtos e processos, seja em aspecto micro, regional ou nacional (FREEMAN, 1995; LEMOS; CARIO, 2017).

O termo sistema remete aos agentes institucionais que vão garantir uma performance inovadora, mediante as interações entre os componentes do grupo, e o conceito de nacional reporta-se ao ambiente interno de um país que pode favorecer ou inibir a introdução das inovações, dependendo do aporte fornecido pelo Estado e/ou Nação (FREEMAN, 1995; LEMOS; CARIO, 2017).

O sistema de inovação no Brasil, como conceito, ainda está em construção, sua essência e o contexto progrediram, ainda que sua interpretação e medição encontrem-se em estágio introdutório. Assim, a busca por metodologias próprias e pesquisas para medir esse fenômeno apresenta-se em fase de proposições, em que pesquisadores trabalham para definir papéis, estratégias e ações acerca do tema (ACOSTA; ACOSTA; ESPINOZA, 2016; LEMOS; CARIO, 2017).

Pode-se inferir que o Sistema Nacional de Inovação é uma estrutura regulamentada que legitima, delimita e formaliza o papel dos agentes de forma a trazer segurança jurídica e apoio estrutural (fiscal, creditício, relacional) entre e para os agentes. A partir desse sistema espera-se que ao nível micro crie-se "ambientes" de inovação que sejam flexíveis e voltados para demandas mais específicas e próximas de cada micro/mesorregião, dado que os meios interno e externo influenciam o ritmo e os tipos de inovações (ARAÚJO; ROCHA; CARVALHAIS, 2015; SZNITOWSKI; SOUZA, 2016).

Desse ponto de vista, as empresas passam a inovar para garantir a sua permanência no mercado e as universidades passam a estender sua atuação na sociedade, subsidiando o desenvolvimento do país, buscando alianças com empresas, mediante a criação de instituições que impulsionam práticas de P\&D, canais de disseminação de informações científicas, centros de desenvolvimento tecnológico e de pesquisas avançadas (DEWES; DALMARCO; PADULA, 2015; PIRES; QUINTELLA, 2015).

Assim, a inovação é resultante de um processo denso e dinâmico de interações que são espelhadas nas relações entre ciência, pesquisa, desenvolvimento e tecnologia, nas universidades, empresas e governo, levando em conta tanto a capacidade de produzir e assimilar conhecimento quanto a proximidade geográfica dos agentes, balizando constituir uma hélice de transições incontáveis de saberes, que incita a intensificação de microssistemas inovativos (QUANDT; BEZERRA; FERRARESI, 2015; FUENTES; DUTRÉNIT, 2016).

Neste contexto, o objetivo da Triple Helix é criar um ambiente inovador que abarca iniciativas trilaterais fundamentadas no conhecimento, desenvolvimento econômico e alianças estratégicas entre empresas de pequeno, médio e grande portes, operando em áreas distintas e com diferentes níveis de tecnologia, denotando não apenas o relacionamento da universidade, indústria e governo, mas também transformações internas de cada uma dessas esferas, bem como as relações entre as instituições que englobam as três hélices do modelo (ETZKOWITZ; LEYDESDORFF, 2000). 
Diante desse cenário, a inovação torna necessária a capacidade de interação entre todos os agentes produtivos, desde clientes, fornecedores, instituições de pesquisa, empresas de serviços de engenharia, até agências governamentais e concorrentes potenciais, tanto como fonte de informação e aprendizado tecnológico como por meio de contratos de cooperação entre as firmas (DEWES; DALMARCO; PADULA, 2015).

Estudos buscaram conceituar o processo de inovação e diversificação, para o qual Pavitt (1984) contribuiu propondo uma taxonomia de setores econômicos, agregando três esferas: dominado por fornecedores, intensivo em produção e com base na ciência. Assim, à medida que a organização cria ou institui inovações, constrói alinhamento estratégico entre as habilidades tecnológicas, fluxo de conhecimento e vantagens a nível empresarial, regional e, no longo prazo, desenvolvimento nacional (PAVITT, 1984).

Pavitt (1984) teve como objetivo observar a estrutura produtiva das firmas, com foco nas mudanças tecnológicas, pautadas no conhecimento científico, nos fornecedores especializados e na intensidade da escala de produção, em que se legitimou a importância de ações integradas entre as empresas, uma vez que existem assimetrias entre os setores, que quando trabalhadas em conjunto são reduzidas, potencializando a eficiência dos resultados em inovação (PAVITT, 1984).

Nessa perspectiva, é de suma importância a ação deliberada dos agentes públicos e privados envolvidos no contexto da inovação direcionada ao agronegócio, tendo em vista a necessidade de integração e atuação em sinergia entre os produtores rurais e os atores locais, seja na criação de práticas que permitam a disseminação de conhecimentos ou na gestão dos processos de inovação, com o intuito de superar ou minimizar as dificuldades dessa atividade, promovendo o desenvolvimento do entorno e articulando operações conjuntas de marketing e logística (SANTOS et al., 2018).

Tonelli e Zambalde (2009), Dossa e Segatto (2010), Rosa (2014), Schut et al. (2016) são alguns dos autores que em seus trabalhos explanam sobre as vertentes teóricas da abordagem Triple Helix direcionadas ao agronegócio, tendo em vista o papel da inovação.

\section{Ambiente de Inovação Voltado ao Agronegócio Brasileiro}

A atividade agropecuária é uma das práticas econômicas em que há sistemas de inovação setoriais mais desenvolvidos no país, cujos reflexos mostram o estágio de desenvolvimento do agronegócio brasileiro (DUTRÉNIT; RIVERA-HUERTA; VERA-CRUZ, 2016). Com tal característica, o agronegócio posiciona o Brasil como um dos principais players do mercado mundial no que diz respeito à competitividade de seus produtos, despontando como fator vital de avanço científico, autonomia tecnológica e desenvolvimento local (SANTOS et al., 2018).

A inovação brasileira voltada para o agronegócio se fortaleceu ao longo das últimas décadas. Entre os eixos centrais que marcaram sua transição destacam-se a Lei de Proteção de Cultivares (LPC), que estabeleceu uma política de proteção intelectual específica para a agricultura, criação do fundo de fomento ao setor agropecuário (CT-Agronegócio), Lei de Inovação que introduziu medidas de incentivo à pesquisa no ambiente produtivo e a Lei do Bem, que instituiu regimes especiais de tributação e aquisição de bens de capital (SEREIA; STAL; CÂMARA, 2015). 
Nessa direção, as políticas públicas articuladas junto a instituições que disponibilizam recursos para fomento do agronegócio, como o Banco Nacional de Desenvolvimento Econômico e Social (BNDES), o Banco da Amazônia (Basa), a Financiadora de Estudos e Projetos (Finep), a Empresa Brasileira de Pesquisa Agropecuária (Embrapa) e o Ministério da Ciência, Tecnologia e Inovação (MCTIC), trabalham ofertando instrumentos a fim de incentivar e intensificar a produção de conhecimento e de inovação nas empresas brasileiras (KANNEBLEY Jr.; PRINCE, 2015; CIRANI et al., 2016; NOBRE et al., 2016).

No Quadro 1 são apresentados estudos empíricos relevantes que abordam a importância dos ambientes de inovação para a atividade agropecuária, em que estão elencadas suas contribuições para a temática como forma de evidenciar estudos aplicados.

Quadro 1 - Estudos empíricos aplicados referentes à importância dos ambientes de inovação à atividade agropecuária

\begin{tabular}{|c|c|c|c|c|}
\hline Autor/ano & $\begin{array}{l}\text { Local da realiza- } \\
\text { ção }\end{array}$ & Objetivo & Método & Resultado \\
\hline $\begin{array}{l}\text { (SZNITOWSKI; } \\
\text { SOUZA, 2016) }\end{array}$ & $\begin{array}{l}\text { Empreendimen- } \\
\text { tos rurais de } \\
\text { grande porte } \\
\text { no município de } \\
\text { Campo Novo do } \\
\text { Parecis - Mato } \\
\text { Grosso }\end{array}$ & $\begin{array}{l}\text { Analisar as opor- } \\
\text { tunidades de ino- } \\
\text { vação tecnológica } \\
\text { mediante observa- } \\
\text { ção da capacidade } \\
\text { absortiva (CA) dos } \\
\text { conhecimentos lo- } \\
\text { grados no ambiente } \\
\text { de inovação. }\end{array}$ & $\begin{array}{l}\text { O estudo apoiou-se } \\
\text { em dados primários. } \\
\text { Entrevista estrutura- } \\
\text { da. } \\
\text { Utilizou-se o sof- } \\
\text { tware para pesquisa } \\
\text { qualitativa destinada } \\
\text { à análise de conteú- } \\
\text { do e codificação ma- } \\
\text { nual. }\end{array}$ & $\begin{array}{l}\text { Organizações com maio- } \\
\text { res níveis de capacidade } \\
\text { para absorção de conhe- } \\
\text { cimentos são mais pro- } \\
\text { ativas na exploração de } \\
\text { oportunidades. } \\
\text { Aumento da produtivida- } \\
\text { de via diversificação de } \\
\text { culturas, integração de } \\
\text { lavoura e pecuária. }\end{array}$ \\
\hline $\begin{array}{l}\text { (GELINSKI Jr. } \\
\text { et al., 2014) }\end{array}$ & Brasil & \begin{tabular}{|l|} 
Discutir as ques- \\
tões das mudanças \\
estruturais via pro- \\
cessos de inovação \\
tecnológica no con- \\
junto de SI do agro- \\
negócio brasileiro.
\end{tabular} & $\begin{array}{l}\text { Mediante aborda- } \\
\text { gem evolucionária, } \\
\text { foram aprofundadas } \\
\text { as questões da ino- } \\
\text { vação e da constitui- } \\
\text { ção do Sistema de } \\
\text { Inovação da agrope- } \\
\text { cuária, pautado na } \\
\text { teoria neoschumpe- } \\
\text { teriana. }\end{array}$ & $\begin{array}{l}\text { Investimentos no agro- } \\
\text { negócio tendem a ser } \\
\text { vinculados às exporta- } \\
\text { ções. } \\
\text { Há necessidade da pre- } \\
\text { sença do Estado, arti- } \\
\text { culando instituições, } \\
\text { mobilizando recursos, } \\
\text { formando mercados, le- } \\
\text { gitimando a direção de } \\
\text { pesquisas e o desenvolvi- } \\
\text { mento de externalidades } \\
\text { positivas. }\end{array}$ \\
\hline $\begin{array}{l}\text { (MAZZOLENI; } \\
\text { OLIVEIRA, } \\
\text { 2010) }\end{array}$ & \begin{tabular}{|l|} 
Fazenda situada \\
na Região do \\
Centro-O e ste \\
Brasileiro \\
\\
\end{tabular} & $\begin{array}{l}\text { Estudar os aspectos } \\
\text { da inovação no pro- } \\
\text { cessamento pós- } \\
\text {-colheita de uma } \\
\text { fazenda, conside- } \\
\text { rando a certificação } \\
\text { e evolução históri- } \\
\text { ca da inovação na } \\
\text { agricultura. }\end{array}$ & $\begin{array}{l}\text { Estudo de caso em } \\
\text { uma agroindústria. } \\
\text { Entrevistas com ge- } \\
\text { rentes e proprietá- } \\
\text { rio. }\end{array}$ & $\begin{array}{l}\text { Modificações no ambien- } \\
\text { te interno da empresa e } \\
\text { a adoção de uma série de } \\
\text { normas técnicas e certifi- } \\
\text { cação viabilizaram o pro- } \\
\text { cesso de inovação. }\end{array}$ \\
\hline $\begin{array}{l}\text { (FRIEDERICHSEN } \\
\text { et al., 2013) }\end{array}$ & $\begin{array}{l}\text { Quatro provín- } \\
\text { cias do Vietnã - } \\
\text { Son La, Phú Yên, } \\
\text { Mai } \\
\text { Sơn e Yên, Châu }\end{array}$ & $\begin{array}{l}\text { Identificar a impor- } \\
\text { tância de um sis- } \\
\text { tema de inovação } \\
\text { para a agricultura } \\
\text { que seja capaz de } \\
\text { se adequar ao am- } \\
\text { biente de cada re- } \\
\text { gião. }\end{array}$ & $\begin{array}{l}\text { Entrevistas e análise } \\
\text { qualitativa realizada } \\
\text { em duas etapas. } \\
\text { Utilizou-se software } \\
\text { mediante a criação } \\
\text { de códigos, pauta- } \\
\text { dos no material em- } \\
\text { pírico. }\end{array}$ & $\begin{array}{l}\text { Governo é identificado } \\
\text { como fator-chave para o } \\
\text { aumento da capacidade } \\
\text { de inovação nas terras } \\
\text { rurais. }\end{array}$ \\
\hline
\end{tabular}




\begin{tabular}{|c|c|c|c|c|}
\hline $\begin{array}{ll}\text { (TURNER } \\
\text { al., 2017) }\end{array}$ & Nova Zelândia & $\begin{array}{l}\text { Entender por meio } \\
\text { de dois projetos } \\
\text { que abordaram a } \\
\text { agricultura e a ter- } \\
\text { ra, os problemas } \\
\text { de gestão com di- } \\
\text { ferentes níveis de } \\
\text { complexidades e } \\
\text { a importância da } \\
\text { inovação nesse am- } \\
\text { biente. }\end{array}$ & $\begin{array}{l}\text { Estudo de caso. } \\
\text { Entrevistas semies- } \\
\text { truturadas e dados } \\
\text { secundários. }\end{array}$ & $\begin{array}{l}\text { Utilização de capacidade } \\
\text { adaptativa para explorar } \\
\text { e criar novas oportunida- } \\
\text { des de inovação. } \\
\text { Configurações para res- } \\
\text { ponder a circunstâncias } \\
\text { emergentes de acordo } \\
\text { com o ambiente. }\end{array}$ \\
\hline $\begin{array}{l}\text { ( B ATA L HA ; } \\
\text { CHAVES; SOU- } \\
\text { ZA FILHO, } \\
\text { 2009) }\end{array}$ & $\begin{array}{l}\text { Instituições Bra- } \\
\text { sileiras }\end{array}$ & $\begin{array}{l}\text { Identificar e mensu- } \\
\text { rar todos os gastos } \\
\text { em C\&T e I para a } \\
\text { produção agrope- } \\
\text { cuária no Brasil, } \\
\text { tanto em termos da } \\
\text { natureza das ino- } \\
\text { vações quanto do } \\
\text { volume de investi- } \\
\text { mentos necessários } \\
\text { nesse ambiente. }\end{array}$ & $\begin{array}{l}\text { Pesquisa descritivo- } \\
\text {-quantitativa. } \\
\text { Aplicação de ques- } \\
\text { tionários. } \\
\text { Foram analisados os } \\
\text { investimentos reali- } \\
\text { zados por } 48 \text { institui- } \\
\text { ções de apoio e de } \\
\text { pesquisa brasileiras. }\end{array}$ & $\begin{array}{l}\text { Inovação é um fenôme- } \\
\text { no complexo e dinâmico. } \\
\text { Embrapa tem papel pre- } \\
\text { ponderante no Sistema } \\
\text { Nacional de Pesquisa } \\
\text { Agropecuária. } \\
\text { Existem lacunas e entra- } \\
\text { ves ao desenvolvimento } \\
\text { científico e tecnológi- } \\
\text { co voltado para o setor } \\
\text { agropecuário. }\end{array}$ \\
\hline
\end{tabular}

Fonte: Elaborado pelos autores (2019).

Diante das considerações que foram apresentadas, notadamente diferentes trabalhos discutem a importância de ambientes de inovação em estudos aplicados. Verificou-se de modo geral a importância do Estado como provedor de um ambiente propício à inovação, como apresentado nos trabalhos de Gelinski Jr. et al. (2014) e Friederichsen et al. (2013); outras contribuições importantes são encontradas nos artigos de Sznitowski e Souza (2016) e Mazzoleni e Oliveira (2010) no tocante à relevância dos conhecimentos adquiridos com os processos inovativos e seus desdobramentos para o agronegócio.

Turner et al. (2017) em trabalho similar defendem a necessidade da criação de oportunidades no ambiente que desencadeiem a inovação; por sua vez, Batalha, Chaves e Souza Filho (2009) em seus estudos tratam da importância e reconhecimento da Empresa Brasileira de Pesquisa Agropecuária (Embrapa) e suas contribuições para o desenvolvimento da pesquisa nesta que é a mais relevante e competitiva atividade econômica do país.

Os trabalhos que circundam o tema inovação no agronegócio caracterizam-na como principal atributo definidor de vantagem competitiva, responsável por garantir o crescimento econômico, a autonomia tecnológica e o desenvolvimento industrial do país (DOSSA; SEGATTO, 2010; LEMOS; CARIO, 2017).

Nessa conjuntura, é de vital importância a integração de múltiplos agentes, alicerçados pela pesquisa, educação e extensão, via universidades focadas em promover a inovação com ênfase nos produtores e nas unidades agropecuárias (SANTOS et al., 2018). Tais considerações ratificam o exposto no Quadro 1 e trazem à luz a relevância de unidades de ensino e pesquisa ativas no âmbito da inovação. 


\section{MATERIAIS E MÉTODOS}

A orientação metodológica desta pesquisa tem natureza aplicada, com finalidades exploratória e descritiva, a partir do método do estudo de caso, cujos resultados foram analisados por uma abordagem quantitativa e qualitativa (GIL, 2008). Essa estratégia permitiu alcançar os objetivos e as motivações para o estudo, a partir de uma realidade empírica na qual o ambiente de inovação não apresenta um sistema de gestão integrado.

Os materiais foram obtidos em três fontes: i) bases de dados de agências de fomento distintas (CNPq, Fapesp, Capes, Funep); ii) Plataforma Lattes e iii) Registros da Faculdade de Ciências Agrárias e Veterinárias (FCAV).

A FCAV é um campus complexo com 5 cursos de Graduação, 11 programas de Pós-Graduação (stricto sensu) com 21 cursos (Mestrado/Doutorado e Mestrado Profissional), Hospital Veterinário Universitário, Fazenda de Pesquisa e Extensão, múltiplos grupos de pesquisa nos quais atuam 179 docentes e 3 pesquisadores, 1.172 alunos de Graduação e 814 de Pós-Graduação (FCAV, 2018).

Diante disso, delimitações são importantes para a realização da pesquisa. São elas: i) temporal: os materiais foram tomados entre os anos de 2011 e 2016 e ii) espacial: foram considerados na amostra somente os professores credenciados como permanentes na Pós-Graduação e pesquisadores.

Assim, para elaborar a base de dados que fundamenta o trabalho, foram elencados os professores credenciados da Pós-Graduação da FCAV que formam a amostra de análise com 295 docentes, observando-se que existem docentes contados com repetição, pois estes estão vinculados a mais de um programa da Pós-Graduação. Como tem-se resultados por programa (publicações, orientações, entre outros) foi necessário contabilizar os professores com atuação em dois programas duas vezes. O foco na Pós-Graduação é decorrente da pertinência de tais programas o processo de CT\&I, tanto pela formação de profissionais pesquisadores como pela pesquisa associada.

Utilizou-se na construção da base de dados os Índices de Produção por Docente (IPD) e Média de Produção por Docente (MPD), ${ }^{3}$ com informações quinquenais que atendem ao período da pesquisa, as quais foram coletadas por meio do portal da Pró-Reitoria de Pesquisa da Unesp (PROPe) a partir da seleção da faculdade de interesse, e posteriormente dos departamentos e professores que ela compreende.

A partir da Plataforma Lattes foram reunidos os dados referentes ao número de orientações concluídas em Trabalhos de Conclusão de Curso, Mestrado, Doutorado e Pós-Doutorado; artigos publicados; número de projetos com financiamentos externos públicos (CNPq, Capes, Fapesp) e privados (empresas), mediante o acesso do currículo e soma de cada item listado, para cada pesquisador que compõe o corpo docente da FCAV, dentro do período de tempo proposto.

\footnotetext{
${ }^{3}$ Os índices são calculados por uma fórmula que contabiliza as principais produções científicas por docente. São elas: artigos publicados em periódicos nacionais e internacionais, livros e capítulos de livros.
} 
Fundamentado no acesso à base de dados Scopus, foram selecionados um a um os pesquisadores que integram o estudo, a fim de verificar a quantidade de citações registradas na base, por meio da elaboração de um filtro que abarca o Estado, o nome e a cidade em que a Universidade está localizada, para evitar problemas com nomes ou sobrenomes iguais.

Alicerçado no Google Scholar, foram investigados a quantidade de citações e o Índice $\mathrm{H}$ do pesquisador, a partir da consulta do perfil de cada docente, mediante inserção do seu nome completo.

Os indicadores referentes à quantidade de orientações com bolsa de órgão público e privado de cada docente foram solicitados à Fundação de Apoio à Pesquisa, Ensino e Extensão (Funep).

Esse conjunto de informações possibilitou a construção das variáveis previstas no Quadro 2. Esses dados foram tratados pelo modelo de análise discriminante, em razão da sua capacidade de estabelecer se existem diferenças estatisticamente significantes entre o perfil do escore médio em um conjunto de variáveis para os grupos determinados (HAIR JR. et al., 2009).

Quadro 2 - Variáveis da Pesquisa

\begin{tabular}{|c|l|l|}
\hline Dimensão & \multicolumn{1}{|c|}{ Variável } & \multicolumn{1}{|c|}{ Fonte } \\
\hline \multirow{4}{*}{ Docente } & Projetos com financiamento externo público & Lattes \\
\cline { 2 - 3 } & Orientação de TCC & Lattes \\
\cline { 2 - 3 } & Orientação de Mestrado & Lattes \\
\cline { 2 - 3 } & Orientações com bolsa de órgão público & Lattes \\
\cline { 2 - 3 } & Orientação de Doutorado e Pós-Doutorado & Lattes \\
\cline { 2 - 3 } & Índice de Produção por Docente (IPD) & PROPe \\
\cline { 2 - 3 } & Média de Produção por Docente (MPD) & PROPe \\
\hline \multirow{5}{*}{ CT\&l } & Artigos publicados em revistas qualificadas & Lattes \\
\cline { 2 - 3 } & Número de citações na plataforma Scopus & Scopus \\
\cline { 2 - 3 } & Número de citações no Google Scholar & Google \\
\cline { 2 - 3 } & Índice H & Lattes \\
\hline
\end{tabular}

Fonte: Elaborado pelos autores (2019).

Quanto ao método, aplicou-se a análise discriminante com objetivo de analisar se o desempenho dos docentes era influenciado quando este realizava projetos com empresas. Assim, buscou-se discriminar os docentes em dois grupos: i) aqueles que possuem projetos de pesquisa, ensino ou extensão com empresas; ii) docentes que não possuem projetos de pesquisa, ensino ou extensão com empresas.

Desta forma, como estudo de caso, tem-se múltiplas fontes de informação que permitiram a construção da análise dos resultados integrando os quantitativos e os qualitativos de forma imparcial.

\section{RESULTADOS E DISCUSSÕES}

Essa seção apresenta os resultados obtidos a partir da análise acerca da relação Universidade-Empresas para o desempenho acadêmico da FCAV. Esses resultados foram gerados mediante análise discriminante dos dados. 
A FCAV é uma das faculdades mais tradicionais da Unesp e uma das líderes na produção científica e na captação de recursos junto aos órgãos de fomento dentro da universidade (FCAV, 2018). Além da robustez no ensino, a unidade destaca-se pelas atividades de pesquisa e prestação de serviços à comunidade, tendo em vista que o município de Jaboticabal está localizado em uma das mais ricas regiões do Estado de São Paulo, cujo quadro econômico é aquecido principalmente pela produção agrícola, contribuindo para que os eixos centrais de atuação da FCAV sejam as cadeias agropecuárias (SANTOS et al., 2018).

Com vistas ao desenvolvimento, a FCAV atua via convênios e parcerias junto a Funep, prefeitura, empresas e produtores rurais, integrando docentes e discentes em ações que visam à melhoria dos índices de produtividade e desempenho. Diante desse cenário, a Figura 1 elucida que o Índice de Produção por Docente (IPD) na FCAV é maior se comparado ao IPD que agrega todas as unidades da Unesp. Tal fator confirma a expressividade da FCAV no que respeita à formação de profissionais (acadêmicos e não acadêmicos) e o desenvolvimento de pesquisas.

Figura 1 - Índice de Produção por Docente

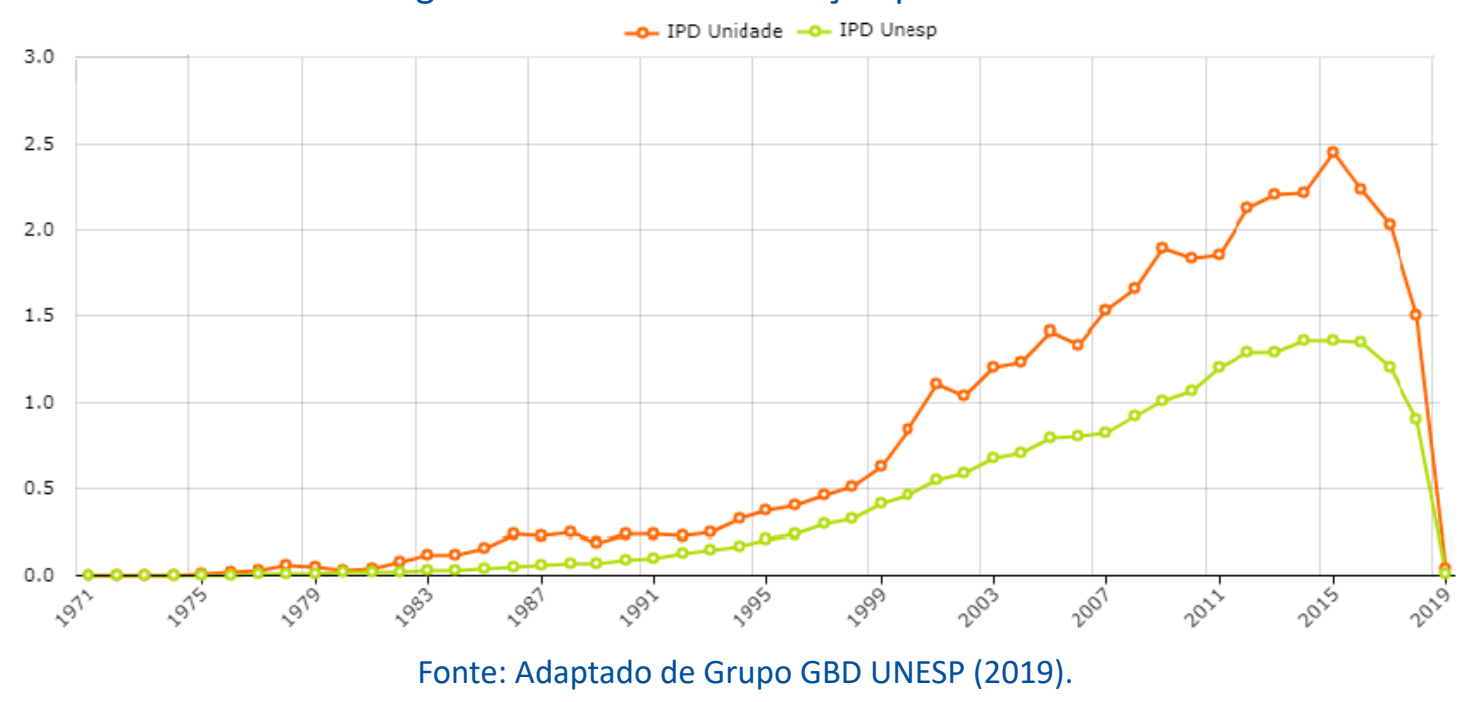

Considerando a pergunta que motivou esse estudo, tem-se o objetivo de avaliar o desempenho acadêmico de docentes que viabilizam a estratégia da relação Universidade-Empresas. Utilizou-se os projetos científicos e tecnológicos financiados por empresas por meio da Funep como critério para discriminar os docentes que possuem relacionamento com as empresas daqueles que não tem.

Tal escolha também está atrelada à importância da Funep para a FCAV, tendo em vista que a Fundação tem como uma de suas metas promover e fomentar o desenvolvimento técnico-científico e institucional, além de conceder bolsas de auxílio ao estudo e à pesquisa, fatores-chave para alcançar o objetivo desse estudo (FUNEP, 2019).

Kannebley Júnior e Prince (2015) e Cirani et al. (2016) chamam a atenção em seus estudos para a relevância de fundações de amparo à pesquisa como a Funep, haja vista o papel crucial dessas instituições para a produção científica e tecnológica nas universidades. Paralelamente, é importante frisar a pertinência dessas instituições para o êxito da interação Universidade-Empresas, sobretudo no tocante à captação de recursos e subsídios (BASTOS; BRITTO, 2017). 
A Unesp possui outras 17 Fundações de apoio, incluindo a Fundunesp, que abrange todas as unidades. A Funep, no entanto, é uma das Fundações mais antigas da universidade e benchmark em processos, totalmente auditados pelos órgãos de controle (FUNEP, 2019). Nesse sentido, não se teve conhecimento de docentes da FCAV com pesquisas junto ao mercado gerenciadas por outra Fundação.

Diante desse critério de segregação, verificou-se que a FCAV contou entre 2011 e 2016 com 168 docentes com projetos na Funep, o que representa 52\% do total da FCAV. Esses docentes constituem o "Grupo 1", logo, os docentes que não apresentaram projetos com o mercado estão no "Grupo 0".

A Tabela 1 apresenta os resultados da análise discriminante para a amostra de observação.

Tabela 1 - Análise Discriminante

\begin{tabular}{|c|c|c|c|c|c|c|c|}
\hline Variáveis & $\begin{array}{l}\text { Média } \\
\text { Grupo } 0\end{array}$ & $\begin{array}{c}\text { Média } \\
\text { Grupo } 1\end{array}$ & $\begin{array}{l}\text { Média da } \\
\text { amostra }\end{array}$ & $\begin{array}{l}\text { Erro Desvio } \\
\text { da Amostra }\end{array}$ & $\begin{array}{l}\text { Lambda } \\
\text { de Wilks }\end{array}$ & $\mathbf{Z}$ & Significância \\
\hline $\begin{array}{l}\text { Projetos com } \\
\text { Financiamento } \\
\text { Externo Público }\end{array}$ & 3 & 5 & 4 & 5 & 0,953 & 14,475 & 0,000 \\
\hline Orientações de TCC & 3 & 7 & 5 & 7 & 0,945 & 17,203 & 0,000 \\
\hline $\begin{array}{l}\text { Orientações de } \\
\text { Mestrado }\end{array}$ & 6 & 7 & 7 & 5 & 0,981 & 5,554 & 0,019 \\
\hline $\begin{array}{l}\text { Orientações de } \\
\text { Doutorado }\end{array}$ & 5 & 5 & 5 & 4 & 0,998 & 0,641 & 0,424 \\
\hline Número de Artigos & 34 & 34 & 34 & 26 & 1 & 0,084 & 0,772 \\
\hline $\begin{array}{l}\text { Número de Citações } \\
\text { Scopus }\end{array}$ & 399 & 449 & 428 & 1.050 & 0,999 & 0,16 & 0,689 \\
\hline Índice $\mathrm{H}$ & 8 & 8 & 8 & 7 & 1 & 0,009 & 0,925 \\
\hline $\begin{array}{l}\text { Índice de Produção } \\
\text { por Docente }\end{array}$ & 2 & 3 & 3 & 2 & 0,998 & 0,488 & 0,485 \\
\hline $\begin{array}{l}\text { Média de Produção } \\
\text { por Docente }\end{array}$ & 5 & 5 & 5 & 5 & 0,994 & 1,854 & 0,174 \\
\hline Número de Docentes & 127 & 168 & n.a. & n.a. & n.a. & n.a. & n.a. \\
\hline
\end{tabular}

Nota: Estatística M de Box =44,83; Significância ( $p$-valor = 0,000).

Fonte: Elaborado pelos autores (2019).

O Teste $M$ de Box $(44,83, p$-valor $=0,000)$ rejeitou a hipótese nula da igualdade das matrizes de covariância entre os grupos (HAIR Jr. et al., 2009). Os Lambdas de Wilks são próximos a 1 e sinalizam que não há maiores diferenças de variações entre as médias dos dois grupos.

De imediato é possível verificar que o desempenho acadêmico em todas as dimensões apontadas é similar, observando-se que, em nenhuma das variáveis estudadas a performance dos docentes com recursos junto ao mercado é inferior àqueles que não possuem.

Diante desse cenário, pode-se inferir que a maior proximidade dos docentes com as empresas não traz prejuízos acadêmicos e não afeta negativamente a instituição de ensino. Tal constatação contrapõe algumas das críticas acerca da relação Universidade-Empresas, sobretudo aquelas que argumentam sobre o declínio da produção acadêmica resultante desse relacionamento, como é o caso dos estudos de Santana e Porto (2009) e Berni et al. (2015). 
Ainda nessa vertente, em contrapartida ao estudo de Machado e Sartori (2018), a partir dos resultados deste trabalho verificou-se que a cooperação entre Universidade-Empresas não apresenta dificuldades para a captação de recursos (privados ou públicos), tendo em vista que no caso da FCAV os professores que têm projetos na Funep são os que mais obtêm recursos. Assim, tais docentes, além de não apresentarem dicotomia à universidade, ajudam os demais a obterem recursos públicos, tendo em vista o viés acadêmico e o impacto de suas publicações.

Nessa direção, constata-se que os docentes com atuação no mercado também são aqueles que apresentam uma maior quantidade de orientações nos níveis de Graduação e Mestrado, bem como no número de projetos financiados com recursos públicos. Assim, constata-se que uma maior aproximação com o mercado para o financiamento de pesquisas e bolsas é salutar para o ambiente de CT\&l das universidades (LEMOS; CARIO, 2017).

Percebe-se, também, que a média das citações/docente daqueles que apresentam parcerias com o mercado é maior em comparação com aqueles que não possuem, além do nível de publicação no período ser semelhante, podendo-se compreender que as publicações do Grupo 1 apresentam maior impacto em relação àquelas do Grupo 0, corroborando as asseverações de Herculano e Norberto (2012), quanto à necessidade de buscar um foco maior em pesquisas que gerem publicações de impacto para a universidade e para a sociedade.

Nesse sentido, Herculano e Norberto (2012) discorrem que variáveis encarregadas de quantificar a produtividade dos docentes e seu índice de impacto têm seus resultados associados ao perfil do docente, isso é, a visibilidade, prestígio e confiabilidade do docente junto aos órgãos de fomento, em que para a FCAV verificou-se que ter projetos junto a Funep resulta em maior facilidade para captação de recursos junto aos órgãos de apoio à pesquisa.

Todos os resultados sinalizam que o envolvimento dos docentes em projetos com empresas para geração de tecnologia não concorre com os outros objetivos da FCAV, e sim o oposto, certas variáveis têm maiores resultados a partir da relação Universidade-Empresas, conforme Tabela 2.

Tabela 2 - Variáveis discriminantes

\begin{tabular}{l|r|r|r|r|r|r|r|r}
\hline \multicolumn{1}{c|}{ Variáveis } & Estatística & Df 1 & Df 2 & Df 3 & Estatística & Df 1 & Df 2 & Sig. \\
\hline $\begin{array}{l}\text { Projetos com Financiamento } \\
\text { Externo Público }\end{array}$ & 0,897 & 2 & 1 & 293 & 16,822 & 2 & 292 &, 000 \\
\hline Orientações de TCC & 0,945 & 1 & 1 & 293 & 17,203 & 1 & 293 &, 000 \\
\hline
\end{tabular}

Fonte: Elaborado pelos autores (2019).

Avaliando todas as variáveis, somente os projetos com financiamento externo público e as orientações de TCC discriminam estatisticamente os grupos determinados $a$ priori, de acordo com a Tabela 2.

Interessante destacar que, como os docentes com projetos na Funep são os que mais captam recursos, essa capacidade constitui um recurso organizacional da FCAV e ajuda a discriminar o perfil dos seus docentes (OLIVEIRA, 2016; LEMOS; CARIO, 2017). 
Tal proposição vai ao encontro das considerações de Lemos e Cario (2017) acerca da relevância e papel determinante das instituições de fomento na consolidação de pesquisas.

Esse resultado demonstra que a captação de recursos em fontes privadas não é excludente à captação em fontes públicas, ao contrário; essa condição sugere que a competência na captação de recursos e a habilidade na gestão de projetos podem ser complementares e se apoiarem mutuamente.

Quanto às orientações, percebe-se que docentes com projetos junto a Funep espelham o mesmo desempenho daqueles que não o fazem, confirmando que a relação Universidade-Empresas não compromete a produtividade acadêmica desses profissionais, ao contrário, o Grupo 1 apresentou médias superiores para orientações de TCC e de Mestrado.

Ainda nessa perspectiva, Kannebley Jr., Carolo e Negri (2013) discorrem quanto à relevância de sinergia entre os esforços dos docentes tanto para as orientações voltadas à Graduação, como para aquelas direcionadas à Pós-Graduação, cujo entendimento para FCAV deriva do alinhamento entre esse número, seja para os docentes com projetos na Funep seja para os que não possuem. Adicionalmente, percebe-se que os professores estão comprometidos com ambas as vertentes de formação, tendo em vista a similaridade das médias, em que pese o destaque para Grupo 1.

Enfatiza-se a partir desses resultados a relevância da atuação conjunta entre universidades e empresas, vigorando como fator de ajuda mútua para alcançar os respectivos objetivos, contudo importa também postular que tal associação deve ser pensada para agregar valor para seus agentes, uma vez que os docentes já carregam em sua carga horária as funções relativas a ensino, pesquisa e extensão, e sobrecarregá-los tende a impactar negativamente no seu desempenho acadêmico, culminando em queda no montante de publicações e inércia nas pesquisas (SANTANA; PORTO, 2009).

\section{CONSIDERAÇÕES FINAIS}

A relação Universidade-Empresas é explorada sobremaneira pelas chamadas universidades inovadoras, instituições caracterizadas por discentes e docentes com condutas voltadas ao empreendedorismo, e que quando inseridos em um ecossistema universitário favorável, a partir da combinação infraestrutura de qualidade e capital financeiro disponível, promovem desenvolvimento econômico e social.

Respaldadas na abordagem da Triple Helix, as universidades têm em seu âmago o papel de produzir conhecimento e formação de qualidade, mediante criação de ambientes que incentivem a combinação de esforços em atividades empresariais e acadêmicas, em razão do notório benefício de tal cooperação para as instituições que englobam as hélices do modelo.

Isso posto, é importante ressaltar que o desempenho acadêmico de uma universidade perpassa diretamente pelo trabalho dos seus docentes que, em última instância, são os vértices que convergem as ações em ensino, pesquisa e extensão, além de atuarem como dirigentes nas práticas de interação entre a universidade e as empresas. 
Diante desse cenário, foram considerados todos esses fatores com intuito de avançar na discussão acerca dos prós e contras da relação Universidade-Empresas para o desempenho dos docentes, com vistas a responder à questão que motivou a realização deste estudo e alcançar o objetivo da pesquisa.

Assim, todos os resultados obtidos sinalizam que o envolvimento dos docentes da FCAV em projetos com empresas para geração de tecnologia não concorrem com os outros objetivos da instituição, e sim o oposto, certas variáveis têm maiores rendimentos a partir da relação Universidade-Empresas, caso dos projetos com financiamento externo público e as orientações de TCC.

No que respeita à performance dos docentes, pode-se ratificar que o desempenho acadêmico em todas as dimensões apontadas é similar, destacando-se que em nenhuma das variáveis estudadas o rendimento dos docentes com recursos junto ao mercado, Grupo 1, é inferior àqueles que não possuem, Grupo 0.

Diante de tais fatos, nota-se que os docentes com atuação junto ao mercado também são aqueles que apresentam uma maior quantidade de orientações nos níveis de Graduação e Mestrado, bem como no montante de projetos financiados com recursos públicos.

Convém explanar que, apesar da relação Universidade-Empresas não ter impactado de forma negativa no desempenho dos docentes, sinalizando até benefícios para o caso da FCAV, ainda existem ajustes necessários tanto por parte das empresas quanto por parte das universidades, para que tal relacionamento gere frutos no longo prazo e que possam ser revertidos para a sociedade. Essa proposição repousa no fato de que a cooperação ainda é vista por alguns gestores como mero patrocínio e não como uma parceria produtiva.

Desta forma, este trabalho apresenta implicações para o meio acadêmico, na medida em que denota as possibilidades de avanço no que diz respeito à criação de tecnologias e inovação; para o âmbito empresarial, dado que discorre acerca da importância das organizações atuarem como agentes transformadores, convertendo pesquisas em produtos e serviços comercializáveis; e para o Estado, à proporção que evidencia seu papel de intermediário legal, responsável por definir políticas públicas e fomentar financeiramente pesquisas e inovações.

Mostram-se como limitações da pesquisa a impossibilidade de segregar o docente, quando este tem vínculo com mais de um curso de Graduação da FCAV, além da restrição da amostra em virtude do número reduzido de observações. Concomitantemente, têm-se as dificuldades relacionadas à mutabilidade dos aspectos políticos, econômicos e empresariais no cenário brasileiro, que impactam diretamente os pilares da Triple Helix e por conseguinte a intensidade da relação entre Universidade-Empresas.

Para trabalhos futuros sugere-se investigar métodos para gestão da inovação e propriedade intelectual provenientes da relação Universidade-Empresas, apontados na literatura como um dos principais entraves para tal interação. Não obstante, pode-se desenvolver uma avaliação direcionada a estudos de múltiplos casos, separando os docentes por área de conhecimento, com vistas a avaliar de maneira mais ampla seu impacto, considerando que uma análise comparativa a esse nível possibilitaria identificar alguns pormenores dessa relação. 
Além disso, fundamentado na constatação de que o elo entre Universidade-Empresas não traz prejuízos acadêmicos, ao contrário, resulta em maior captação de recursos para as universidades e tem grande potencial para gerar diferenciais competitivos para as empresas, é interessante estudar meios para minimizar as barreiras burocráticas oriundas de tal associação, com vistas a promover no longo prazo o desenvolvimento acadêmico, econômico e social.

\section{REFERÊNCIAS}

ACOSTA, B.; ACOSTA, M.; ESPINOZA, B. Understanding innovation based on company optics: interpretation mistakes on the types of innovation developed. Revista de Administração e Inovação, v. 13, n. 4, p. 295-304, 2016.

ARAÚJO, R. F. D.; ROCHA, E. M. P. D.; CARVALHAIS, J. N. Inovações em organizações públicas: estudo dos fatores que influenciam um ambiente inovador no Estado de Minas Gerais. Revista de Administração e Inovação, v. 12, n. 3, p. 7-27, 2015.

ARBIX, G.; MIRANDA, Z. Políticas de Inovação em nova chance. Estudos Avançados, v. 31, n. 90, p. 1-25, 2017.

BASTOS, C. P.; BRITTO, J. Inovação e geração de conhecimento científico e tecnológico no Brasil: uma análise dos dados de cooperação da Pintec segundo porte e origem de capital. Revista Brasileira de Inovação, v. 16, n. 1, p. 35-62, 2017.

BATALHA, M. O.; CHAVES, G. D. L. D.; SOUZA FILHO, H. M. D. C\&T e I para a produção agropecuária brasileira: mensurando e qualificando gastos públicos. Revista de Economia e Sociologia Rural, v. 47, n. 1, p. 123-146, 2009.

BERBEGAL-MIRABENT, J.; RIBEIRO-SORIANO, D. E.; GARCÍA, J. L. S. Can a magic recipe foster university spin-off creation? Journal of Business Research, v. 68, n. 11, p. 2.272-2.278, 2015.

BERNI, J. C. A. et al. Interação Universidade-Empresa para a inovação e transferência de tecnologia. Revista Gestão Universitária na América Latina, v. 8, n. 2, p. 258-277, 2015.

CALCAGNINI, G.; FAVARETTO, I. Models of university technology transfer: analyses and policies. Journal of Technology Transfer, v. 41, p. 1-6, 2015.

CARVALHO, L. C. D.; MACHADO, D. D. P. N. Ambiente de Inovação: estudo comparativo entre três unidades de uma organização do setor metal-mecânico. Revista de Empreendedorismo e Gestão de Pequenas Empresas, v. 2, n. 1, p. 47-76, 2013.

CHIARINI, T.; VIEIRA, K. P. Universidades como produtoras de conhecimento para o desenvolvimento econômico: sistema superior de ensino e as políticas de CT\&I. Revista Brasileira de Economia, v. 66, n. 1, p. 117-132, 2012.

CIRANI, C. B. S. et al. The Role of Public Institutions for Innovation Support in Brazil. Brazilian Business Review, v. 13, n. 6, p. 210-230, 2016.

CLOSS, L. et al. Intervenientes na Transferência de Tecnologia Universidade-Empresa: o Caso PUCRS. Revista de Administração Contemporânea, v. 16, n. 1, p. 59-78, 2012.

COSTA, P. R. D. et al. Global Organization of Innovation and Cooperability in Brazilian Multinationals. Journal of Technology Management \& Innovation, v. 12, n. 1, p. 13-25, 2017.

CROSSAN, M. M.; APAYDIN, M. A Multi-Dimensional Framework of Organizational Innovation: A Systematic Review of the Literature. Journal of Management Studies, v. 47, n. 6, p. 1.154-1.179, 2010.

DABIC, M.; GONZÁLEZ-LOUREIRO, M.; DAIM, T. U. Unraveling the attitudes on entrepreneurial universities: The case of Croatian and Spanish universities. Technology in Society, v. 42, p. 167-178, 2015.

DEWES, M. D. F.; DALMARCO, G.; PADULA, A. D. Innovation policies in Brazilian and Dutch aerospace industries: How sectors driven by national procurement are influenced by its S\&T environment. Space Policy, v. 34, p. 32-38, 2015.

DIAS, A. A.; PORTO, G. S. Gestão de transferência de tecnologia na Inova Unicamp. Revista de Administração Contemporânea, v. 17, n. 3, p. 263-284, 2013.

DOSSA, A. A.; SEGATTO, A. P. Pesquisas cooperativas entre universidades e institutos públicos no setor agropecuário brasileiro: um estudo na Embrapa. Revista de Administração Pública, v. 44, n. 6, p. 1.3271.352, 2010.

DUTRÉNIT, G.; RIVERA-HUERTA, R.; VERA-CRUZ, A. O. Knowledge flows and linkage with universities: the vision of Mexican farmers. Brazilian Journal of Science and Technology, v. 3, art. 16, p. 1-22, 2016. 
ETZKOWITZ, H.; LEYDESDORFF, L. The dynamics of innovation: from National Systems and "Mode 2" to a Triple Helix of university-industry-government relations. Research Policy, v. 29, p. 109-123, 2000.

FCAV. Faculdade de Ciências Agrárias e Veterinárias. Unesp, 2018. Disponível em: http://www.fcav.unesp. br/. Acesso em: 3 fev. 2018.

FRANKA, A. G. et al. The effect of innovation activities on innovation outputs in the Brazilian industry: Market-orientation vs. technology-acquisition strategies. Research Policy, v. 45, n. 3, p. 577-592, 2016.

FREEMAN, C. The "National System of Innovation" in historical perspective. Cambridge Journal of Economics, v. 19, p. 5-24, 1995.

FRIEDERICHSEN, R. et al. Adapting the innovation systems approach to agricultural development in Vietnam: challenges to the public extension service. Agriculture and Human Values, v. 30, p. 555-568, 2013.

FUENTES, C. D.; DUTRÉNIT, G. Geographic proximity and university-industry interaction: the case of Mexico. The Journal of Technology Transfer, v. 41, p. 329-348, 2016.

FUNEP. Fundação de Apoio à Pesquisa, Ensino e Extensão. Funep, 2019. Disponivel em: http://www.funep.org.br. Acesso em: 1으. 2019.

GARNICA, L. A.; TORKOMIAN, A. L. V. Gestão de tecnologia em universidades: uma análise do patenteamento e dos fatores de dificuldade e de apoio à transferência de tecnologia no Estado de São Paulo. Gestão \& Produção, v. 16, n. 4, p. 624-638, 2009.

GELINSKI JÚNIOR, E. et al. Sistemas de inovação do Agronegócio Brasileiro. Desenvolvimento em Questão, n. 28, p. 279-317, 2014.

GIL, A. C. Métodos e técnicas de pesquisa social. 6. ed. São Paulo: Atlas, 2008.

GRUPO GBD UNESP. Indicadores referentes à produção científica e tecnológica. Portal PROPe, 2019. Disponível em: http://www.institucional.grupogbd.com/PortalPROPe/unesp/fcav/. Acesso em: 20 maio 2019.

HAIR JR., J. F. et al. Análise multivariada de dados. 6. ed. Porto Alegre: Bookman, 2009.

HERCULANO, R. D.; NORBERTO, A. M. Q. Análise da produtividade científica dos docentes da Universidade Estadual Paulista, Campus Marília/SP. Perspectivas em Ciência da Informação, v. 17, n. 2, p. 57-70, 2012.

IACONO, A.; ALMEIDA, C. A. S. D.; NAGANO, M. S. Interação e cooperação de empresas incubadas de base tecnológica: uma análise diante do novo paradigma de inovação. Revista de Administração Pública, v. 45, n. 5, p. 1.485-1.516, 2011.

INEP. Instituto Nacional de Estudos e Pesquisas Educacionais Anísio Teixeira. Censo da Educação Superior 2017. 2017. Disponível em: http://portal.inep.gov.br/artigo/-/asset_publisher/B4AQV9zFY7Bv/content/ mec-e-inep-divulgam-dados-do-censo-da-educacao-superior-2016/21206. Acesso em: 6 abr. 2018.

KANNEBLEY JR., S.; CAROLO, M. D.; NEGRI, F. D. Impacto dos fundos setoriais sobre a produtividade acadêmica de cientistas universitários. Estudos Econômicos, v. 43, n. 4, p. 647-685, 2013.

KANNEBLEY JR., S.; PRINCE, D. D. Restrição financeira e financiamento público à inovação no Brasil: uma análise com base em microdados da Pintec. Nova Economia, v. 25, n. 3, p. 553-574, 2015.

KIEFT, A.; HARMSEN, R.; HEKKERT, M. P. Interactions between systemic problems in innovation systems: The case of energy-efficient houses in the Netherlands. Environmental Innovation and Societal Transitions, v. 24, p. 32-44, 2017.

LEMOS, D. D. C.; CARIO, S. A. F. Os sistemas nacional e regional de inovacão e sua influência na interacão universidade-empresa em Santa Catarina. Revista de Gestão, v. 24, n. 1, p. 45-57, 2017.

LUNDBERG, H. Triple Helix in practice: the key role of boundary spanners. Journal of Innovation, v. 16, p. 211-226, 2013.

MACHADO, D. D. P. N.; BARZOTTO, L. D. C. Ambiente de inovação em instituição hospitalar. Revista de Administração e Inovação, v. 9, n. 1, p. 51-80, 2012.

MACHADO, H. P. V.; SARTORI, R. Conhecimento e inovação no âmbito da cooperação entre universidade e empresa: um estudo de caso. Desenvolvimento em Questão, v. 16, n. 44, p. 483-507, 2018.

MACIEL, M. L. Hélices, sistemas, ambientes e modelos: os desafios à Sociologia da Inovação. Sociologias, n. 6, p. 18-29, 2001.

MAZZOLENI, E. M.; OLIVEIRA, L. G. D. Inovação tecnológica na agricultura orgânica: estudo de caso da certificação do processamento pós-colheita. Revista de Economia e Sociologia Rural, v. 48, n. 3, p. 567-586, 2010.

MCTIC. Ministério da Ciência, Tecnologia, Inovações e Comunicações. Indicadores Nacionais de Ciência, Tecnologia e Inovação 2018. 2018. Disponível em: http://www.mctic.gov.br/mctic/opencms/indicadores/ indicadores_cti.html.

NOBRE, E. A. et al. Capacidade de inovação nas empresas incubadas. Holos, v. 3, p. 198-217, 2016. 
OECD. Oslo Manual: Guidelines for Collecting Reporting and Using Data on Innovation. 4. ed. Paris: OECD and Eurostat, 2018.

OLIVEIRA, J. J. D. Ciência, tecnologia e inovação no Brasil: poder, política e burocracia na arena decisória. Revista de Sociologia e Política, v. 24, n. 59, p. 129-147, 2016.

PAVITT, K. Sectoral patterns of technical change: Towards a taxonomy and a theory. Research Policy, v. 13, n. 6, p. 343-373, 1984.

PIRES, E. A.; QUINTELLA, M. A. T. Política de propriedade intelectual e transferência de tecnologia nas universidades: uma perspectiva do Nit da Universidade Federal do Recôncavo da Bahia. Holos, v. 6, p. 178-195, 2015.

QUANDT, C. O.; BEZERRA, C. A.; FERRARESI, A. A. Dimensões da inovatividade organizacional e seu impacto no desempenho inovador: proposição e avaliação de um modelo. Gestão \& Produção, v. 22, n. 4, p. 873-886, 2015.

ROSA, L. ITSM: um caso de sucesso do Modelo Tríplice Hélice. Revista de Administração da UFSM, v. 7, edição especial, p. 55-69, 2014.

SANTANA, É. E. D. P.; PORTO, G. S. E agora, o que fazer com essa Tecnologia? Um estudo multicaso sobre as possibilidades de transferência de tecnologia na USP-RP. Revista de Administração Contemporânea, v. 13, n. 3, p. 410-429, 2009.

SANTOS, D. F. L. et al. Inovação e desempenho no agronegócio: evidências em uma microrregião do Estado de São Paulo. Desenvolvimento em Questão, v. 16, n. 42, p. 442-483, 2018.

SANTOS, D. F. L.; BASSO, L. F. C.; KIMURA, H. The trajectory of the ability to innovate and the financial performance of the Brazilian industry. Technological Forecasting \& Social Change, v. 127, p. 258-270, 2018.

SCHUT, M. et al. Do mature innovation platforms make a difference in agricultural research for development? a meta-analysis of case studies. Experimental Agriculture, v. 54, n. 1, p. 1-24, 2016.

SEREIA, V. J.; STAL, E.; CÂMARA, M. R. G. D. Fatores determinantes da inovação nas empresas agroindustriais de carne. Nova Economia, v. 25, n. 3, p. 647-672, 2015.

SZNITOWSKI, A. M.; SOUZA, Y. S. D. Capacidade de assimilação de conhecimentos e tecnologias no setor primário: Estudo de casos em grandes propriedade rurais produtoras de soja. Organizações Rurais \& Agroindustriais, v. 18, n. 2, p. 171-185, 2016.

TONELLI, D. F.; ZAMBALDE, A. L. Fatores de sucesso de uma inovação no contexto universitário: um estudo de caso do setor pecuário. Ciência e Agrotecnologia, v. 33, n. 4, p. 1.118-1.124, 2009.

TURNER, J. A. et al. Unpacking systemic innovation capacity as strategic ambidexterity: How projects dynamically configure capabilities for agricultural innovation. Land Use Policy, v. 68, p. 503-523, 2017.

UNESP. Universidade Estadual Paulista. Repositório institucional Unesp. 2019. Disponível em: https://repositorio.unesp.br/. Acesso em: 29 maio 2019. 